\title{
The relationship between insight and affective temperament in bipolar disorder: an exploratory study
}

\author{
A relação entre insight e temperamento afetivo no transtorno bipolar: \\ um estudo exploratório
}

\begin{abstract}
Rafael de Assis da Silva, ${ }^{1,2}$ Daniel C. Mograbi, ${ }^{3,4}$ Evelyn V. M. Camelo, ${ }^{2}$ Luiza Nogueira Amadeo, ${ }^{3}$
\end{abstract}
Cristina M. T. Santana, ${ }^{2,3}$ Jesus Landeira-Fernandez, ${ }^{3}$ Elie Cheniaux ${ }^{2,5}$

\begin{abstract}
Introduction: In recent years, the association between temperament and clinical characteristics of mood disorders has been studied. Most bipolar patients show deficits in their awareness of signs and symptoms. The relationship between affective temperament and insight in bipolar patients has not been carried out in the literature so far.

Objective: To evaluate the relationship between affective temperament and insight in bipolar disorder.

Method: A group of 65 bipolar patients were followed during a year. Patients underwent a clinical assessment and were diagnosed using criteria from the Diagnostic and Statistical Manual of Mental Disorders, 5th edition (DSM-5). Insight was evaluated through the Insight Scale for Affective Disorders (ISAD), and affective temperament, through the TEMPS-Rio de Janeiro. The relationship between affective temperament and insight was explored with Spearman rho correlations between scores on each item of the ISAD and on the TEMPS-Rio de Janeiro subscales.

Results: In euthymic phases, bipolars with depressive temperament were associated with a higher level of insight about the consequences of the disorder; when in mania, patients showed better insight about having an affective disorder, presenting psychomotor alterations, and suffering from guilt or grandiosity. Similarly, bipolar patients with higher scores of anxious temperament, when in mania, had better insight on alterations in attention. Bipolar patients with higher scores of hyperthymic temperament, when in mania, showed the worst insight about thought disorder.

Conclusion: In addition to being determined by the phase of the disease and several varying symptoms, the level of insight in bipolar patients is also influenced by affective temperament. Keywords: Bipolar disorder, insight, affective temperament.
\end{abstract}

\section{Resumo}

Introdução: Nos últimos anos, a associação entre temperamento e características clínicas dos transtornos de humor tem sido estudada. A maioria dos pacientes bipolares apresenta déficits na consciência de sinais e sintomas. A relação entre temperamento afetivo e insight em pacientes bipolares não tem sido relatada na literatura até o momento.

Objetivo: Avaliar a relação entre temperamento afetivo e insight no transtorno bipolar.

Métodos: Um grupo de 65 pacientes bipolares foi acompanhado por um ano. Os pacientes foram submetidos a uma avaliação clínica utilizando os critérios do Manual Diagnóstico e Estatístico de Transtornos Mentais, $5^{a}$ edição (DSM-5). O insight foi avaliado através da Escala de Insight para Transtornos Afetivos (ISAD), e o temperamento afetivo, através da TEMPS-Rio de Janeiro. A relação entre temperamento afetivo e insight foi explorada usando correlações de Spearman entre os escores de cada item da ISAD e as subescalas da TEMPS-Rio de Janeiro.

Resultados: Nas fases eutímicas, os bipolares com temperamento depressivo relacionaram-se com maior nível de insight sobre as consequências do transtorno; quando em mania, apresentaram melhor insight sobre ter um transtorno afetivo, apresentar alterações psicomotoras e sofrer de culpa ou grandiosidade. Da mesma forma, bipolares com maiores escores de temperamento ansioso, quando em mania, tiveram melhor percepção sobre alterações na atenção. Bipolares com escores mais altos de temperamento hipertímico, quando em mania, mostraram o pior insight sobre o curso do pensamento.

Conclusão: $O$ nível de insight em pacientes bipolares, além de ser determinado pela fase da doença e por diversos sintomas, é influenciado pelo temperamento afetivo.

Descritores: Transtorno bipolar, insight, temperamento afetivo.

\footnotetext{
${ }^{1}$ Universidade Federal do Estado do Rio de Janeiro (UNIRIO), Rio de Janeiro, RJ, Brazil. 2 Instituto de Psiquiatria (IPUB), Universidade Federal do Rio de Janeiro (UFRJ), Rio de Janeiro, RJ, Brazil. ${ }^{3}$ Pontifícia Universidade Católica do Rio de Janeiro (PUC-Rio), Rio de Janeiro, RJ, Brazil. ${ }^{4}$ Institute of Psychiatry, Psychology \& Neuroscience, King's College London, London, UK. ${ }^{5}$ Faculdade de Ciências Médicas, Universidade do Estado do Rio de Janeiro (UERJ), Rio de Janeiro, RJ, Brazil.

Submitted Jun 17 2017, accepted for publication Oct 292017.

Suggested citation: Silva RA, Mograbi DC, Camelo EVM, Amadeo LN, Santana CMT, Landeira-Fernandez J, et al. The relationship between insight and affective
} temperament in bipolar disorder: an exploratory study. Trends Psychiatry Psychother. 2018;40(3):210-215. http://dx.doi.org/10.1590/2237-6089-2017-0073 


\section{Introduction}

Temperament may be defined as the fundamental affective attitude, the emotional soundtrack that precedes experience and leads to it. ${ }^{1}$ Emil Kraepelin described four basic affective dispositions - depressive, manic, cyclothymic and irritable - and proposed that imbalance among those was the fundamental cause of the several mental disorders. In his studies, Kraepelin indicated that individuals with a depressive temperament would be better aware of their illness (better insight) and that individuals with hyperthymic temperament would experience worse insight. ${ }^{1}$

The concept of basic affective dispositions has been revisited more recently. Akiskal \& Mallya² and Akiskal ${ }^{3,4}$ have formulated a psychopathological continuum between temperament and mood disorders, redefining the Kraepelinian idea of basic affective states and introducing the concept of a bipolar spectrum. Akiskal has also postulated that temperamental dysregulation would be the fundamental pathology underlying mood disorders and predisposing their development. In recent years, the association between temperament and clinical characteristics of mood disorders has been studied, e.g., evolution, predominant polarity symptomatology, long-term course of disease, suicidality, therapeutic response, and medication adhesion. ${ }^{5-7}$ However, no recent study has addressed the relationship between temperament and insight.

Insight has been traditionally defined as "a correct attitude for morbid change in oneself." ${ }^{8}$ Greater or lesser awareness regarding having a condition, symptoms, and psychosocial impairment may significantly influence the course of disease and thus affect adhesion to treatment. $^{9}$ Studies about insight were initially conducted only on patients with schizophrenia, ${ }^{10,11}$ but now patients with bipolar disorder (BD) have also been investigated. Most patients with $B D$ show deficits in their awareness of signs and symptoms. ${ }^{12}$ The level of insight has been related to several clinical variables, such as number of previous hospitalizations, illness duration, previous psychotic symptoms, and mood state. ${ }^{13,14}$ In addition, correlations between poor insight and cognitive alterations have been found, especially regarding memory, learning, general intelligence, attention, and executive functions. ${ }^{15,16}$ Based on the Kraepelinian concept, we hypothesize that individuals with depressive temperament have better insight and that those with a hyperthymic temperament have worse insight.

The objective of the present study was to evaluate the relationship between affective temperament and insight in $B D$, which, to the best of our knowledge, has not been carried out in the literature so far. Because no previous study has investigated this topic, the current study is exploratory in nature, providing effect sizes for the association between these factors and paving the way for future studies with larger samples.

\section{Methods}

\section{Sample}

This study was performed in an outpatient research clinic at Instituto de Psiquiatria, Universidade Federal do Rio de Janeiro, between July 2014 and June 2015. Inclusion criteria were having a diagnosis of BD type I or type II and being 18 years old. All patients signed an informed consent form. Patients who did not agree to take part in the study or who had serious nonpsychiatric conditions (e.g., congestive heart failure, renal insufficiency) were excluded. The local ethics committee approved the study.

\section{Clinical evaluation}

Psychiatric diagnosis was formulated in this study according to criteria from the Diagnostic and Statistical Manual of Mental Disorders, 5th edition (DSM-5) ${ }^{17}$ and through clinical evaluation conducted by a psychiatrist. Social demographic data were collected (age, sex and educational level). The affective state of each patient was also assessed in each appointment using DSM-5 criteria. The following scales were used: Hamilton Depression Scale (HAM-D), ${ }^{18}$ Young Mania Rating Scale (YMRS), ${ }^{19}$ and Clinical Global Impressions Scale for Use in Bipolar Illness (CGI-BP). ${ }^{20}$ HAM-D is used to assess depressive symptoms with 17 items. YMRS includes 11 items to assess manic symptoms. CGI-BP provides a global scoring on the severity of affective episodes. Patients were evaluated monthly.

Patients were also assessed in each appointment with the Insight Scale for Affective Disorders (ISAD) developed by Olaya et al. ${ }^{21}$ It was translated into Portuguese and adapted for use in Brazil by Silva et al. ${ }^{22}$ The instrument, based on the Scale to Assess Unawareness of Mental Disorders (SUMD), ${ }^{10}$ is a multidimensional assessment consisting of 17 items. Scores ranged from 1 (absence of symptom or full insight) to 5 (no insight) for each item. Therefore, any score above 1 represents alteration of insight regarding a given item.

TEMPS-Rio de Janeiro was also used in the first appointment of euthymic patients. It consists of a reduced questionnaire aimed at assessing affective temperament, based on the Temperament Evaluation of Memphis, Pisa, Paris, and San Diego (TEMPS), ${ }^{23}$ 
and adapted to Brazilian Portuguese. ${ }^{24}$ It has 45 falsetrue questions that allow classifying the temperament of patients into six types: depressive, cyclothymic, hyperthymic, irritable, anxious, or worried. Studies in the U.S. and in Europe have suggested that shorter versions of the TEMPS-A can be just as efficient as the full version, while potentially enhancing respondent compliance. ${ }^{24}$ The internal consistency of the six subscales from TEMPS-Rio de Janeiro is generally good, ranging from 0.67 (anxious subscale) to 0.81 (worrying subscale), with cyclothymic, irritable, depressive, and hyperthymic subscales exhibiting intermediate values $(0.74,0.74,0.72$, and 0.7 , respectively). ${ }^{24}$

Since the same patient could be assessed more than once along the study, thus presenting more than one affective episode, our study opted to only include assessments regarding the first depressive episode, first manic episode, and first euthymic phase of each patient for the sake of the analysis.

\section{Statistical analysis}

Descriptive statistics were used to illustrate sample characteristics. The relationship between affective temperament and insight was explored using Spearman rho correlations between scores obtained on each item of the ISAD and on TEMPS subscales, respecting the ordinal characteristic of the insight scale. Pearson's correlations were calculated between total ISAD scores and affective temperament. The correlational analysis was done separately for each patient group (euthymia, depression and mania). In the case of significant results, partial correlations were calculated with age and educational level to investigate if these factors could explain, partially, the reported associations. Considering the exploratory nature of the current analyses, focus was given to effect sizes (the strength of the correlation) in relation to $\mathrm{p}$-values, with no a priori corrections of $a$, set at 0.05 .

\section{Results}

Sample characteristics and associations between demographic variables and affective temperament

Sixty-five (65) patients with BD were followed along the study. All were evaluated during euthymia at least once. Of the 65 patients, 29 were also evaluated when depressed and 24 when in mania. The sample comprised 43 women and 22 men. A description of demographic and clinical characteristics of the sample can be seen in Table 1.

\section{Associations between insight and affective temperament \\ Euthymia}

A significant correlation was found only between depressive temperament and ISAD \#3 ("Awareness of consequences of the illness on work, family and social life"), with patients with depressive temperament showing better insight ( $\rho=-0.25, p=0.044)$. The results remained unchanged after the inclusion of age or educational level in partial correlations.

\section{Mania}

There was a significant correlation between hyperthymic temperament and worse insight in ISAD \#12 ("Awareness of suffering from idea flight - worse insight with hyperthymic temperament"; $\rho=0.45$, $p=0.025)$. In the partial correlation analysis, this association remained significant when considering age, but was not significant anymore when educational level was included. By contrast, depressive temperament was associated with more preserved insight. This was observed for ISAD \#1 ("Awareness of suffering from an affective disorder"; $\rho=-0.49, p=0.016)$, ISAD \# 8 ("Awareness of suffering from psychomotor agitation"; $\rho=-0.49, p=0.014$ ), and ISAD \#10 ("Awareness of suffering from feelings of grandiosity"; $\rho=-0.44$, $p=0.029)$. These associations remained significant

Table 1 - Sociodemographic and clinical characteristics of participants

\begin{tabular}{lccc}
\hline Variable & $\begin{array}{c}\text { Euthymia }(\mathbf{n}=\mathbf{6 5}) \\
\text { Mean (SD) / Range }\end{array}$ & $\begin{array}{c}\text { Mania }(\mathbf{n}=\mathbf{2 4}) \\
\text { Mean (SD) / Range }\end{array}$ & $\begin{array}{c}\text { Depression }(\mathbf{n}=\mathbf{2 9}) \\
\text { Mean }(\mathbf{S D}) / \text { Range }\end{array}$ \\
\hline Age & $46.4(13.6) / 19-76$ & $46.5(11.5) / 31-63$ & $49.1(14.1) / 19-71$ \\
Sex (\# female/male) & $43 / 22$ & $17 / 7$ & $23 / 6$ \\
Years of education & $10.7(4.2) / 0-17$ & $13.4(4.2) / 4-17$ & $11.2(4.5) / 0-17$ \\
YMRS & $1.4(2.3) / 0-11$ & $18.4(7.3) / 8-31$ & $2.8(3.0) / 0-10$ \\
HAM-D & $2.8(2.7) / 0-10$ & $5.4(4.1) / 1-20$ & $14.4(4.9) / 7-26$ \\
CGI global & $1.2(0.4) / 1-2$ & $4.1(1.1) / 3-6$ & $4.0(1.1) / 3-7$ \\
\hline
\end{tabular}

CGI = Clinical Global Impression scale; HAM-D = Hamilton Depression Rating Scale; SD = standard deviation; YMRS = Young Mania Rating Scale. 
after the inclusion of age and educational level in partial correlations. Similarly, anxious temperament was associated with better insight for awareness of attentional changes (ISAD \#13) in bipolar mania ( $\rho=$ -0.42, $p=0.039$ ), but results reverted to statistical trends when partial correlations were calculated.

\section{Depression}

Significant correlations were found between irritable temperament and ISAD \#2, \#8 and \#10. For ISAD \#2 ("Awareness of treatment efficacy for current symptoms or preventing relapses"), there was better insight with irritable temperament ( $p=-0.38, p=0.044)$, whilst for ISAD \#8 ("Awareness of suffering from sluggishness or psychomotor agitation") and ISAD \#10 ("Awareness of suffering from feelings of uselessness"), insight was worse with irritable temperament (respectively, $\rho=0.42, p=0.024 ; \rho=0.41, p=0.029)$. These associations remained significant with the inclusion of age and educational level in partial correlations for ISAD \# 8 and ISAD \#10, but the association with ISAD\# 2 was no longer significant.

There were no significant correlations between cyclothymic temperament and insight in patients in any mood state.

\section{Discussion}

The present study pioneers the evaluation of the correlations between affective temperament and insight in patients with BD. According to our results, in euthymic phases, higher scores of depressive temperament relate to a higher level of insight about the consequences of the disorder in social life, family, and work. In addition, patients with higher scores of depressive temperament, when in mania, show better insight about having an affective disorder, presenting psychomotor alterations, and suffering from guilt and grandiosity. Similarly, patients with BD with higher scores of anxious temperament, when in mania, have better insight on alterations in attention. Conversely, patients with BD with higher scores of hyperthymic temperament, when in mania, show the worst insight on the course of thought. Patients with higher scores of irritable temperament, when in depression, show better insight of treatment efficacy and worse insight on psychomotor issues and on suffering from guilt or grandiosity.

Affective temperaments are part of the spectrum of affective disorders. ${ }^{4}$ According to Akiskal, the bipolar spectrum encompasses recurrent depressive disorder, dysthymia, depressive, hyperthymic, and cyclothymic temperaments, mixed affective states, hypomania, and BD types I and II. ${ }^{4}$ Recent studies support this concept. ${ }^{25-27}$ Solmi et al., for example, report that affective temperaments are on a continuum, with increasing scores ranging from healthy controls through major depressive disorder to BD. ${ }^{26}$ Our findings support this concept of a "bipolar spectrum." The relationship found between depressive temperament and preserved insight as well as between hyperthymic temperament and impaired insight seems analogous to the one observed between the phases of BD and the level of insight. Several studies do suggest that the level of insight in depression is significantly higher than in mania. ${ }^{28,29}$

Specific affective temperaments might constitute vulnerability factors, as well as clinical picture and illness course modifiers. ${ }^{25}$ Previous studies have shown that patients with depressive or anxious temperament may present mixed characteristics when in mania. ${ }^{30,31}$ Diversely, studies on the insight of patients with BD have found that, when in a mixed episode, patients show better insight than those in pure mania. ${ }^{28}$ Although our study did not differentiate between pure mania and mania with mixed characteristics, it is possible to suggest that depressive and anxious temperaments are important factors for the preservation of insight in mania. Therefore, affective temperaments may somehow be determining for insight in BD.

Kraepelin, in his classical description of affective temperaments, states that individuals with depressive temperament "are more aware of mistakes and deficiencies," that there is "rumination about unhappy moments," and that they are hypercritical. In addition, they more closely observe their physical symptoms, such as tiredness. ${ }^{1}$ Such characteristics may lead those individuals to consider the consequences of their condition more seriously or to report their difficulties more often. The characteristics of the depressive temperament may justify our findings, which showed that, in euthymic periods, higher scores of depressive temperament relate to a higher level of insight about the consequences of the disorder in social life, family and work.

Akiskal et al. ${ }^{32}$ suggest that irritable temperament seems less consistent, since they found underlying scores of depressive, hyperthymic, and cyclothymic temperaments in subjects classified as irritable. Kraepelin, in his classic description, portrays irritable temperament as blending depressive and hyperthymic traits. ${ }^{1}$ It is possible to compare that with the results of studies about insight in BD, since the present study found that patients with irritable temperament, when depressed, show better insight on treatment efficacy. 
That could be a characteristic of individuals with depressive traits and worse insight on psychomotor issues, guilt or grandiosity, which could characterize individuals with hyperthymic temperament.

The idea that affective temperaments associate with clinical aspects in BD seems consistent. Russo et al. ${ }^{33}$ have indeed showed that patients with BD with higher scores of cyclothymic or irritable temperament had better performance in tests of information processing speed, working memory, reasoning, and problem solving. Vöhringer et al. ${ }^{34}$ showed that patients with BD with hyperthymic temperament had more history of suicidality. Azorin et al. ${ }^{35}$ found that patients with $B D$ with hyperthymic and cyclothymic temperaments had stronger association with manic polarity. Finally, Kesebir et al. ${ }^{36}$ reported that patients with $B D$ with irritable temperament had more psychotic symptoms and that the polarity of the first episode tended to be manic more frequently. In addition, individuals with hyperthymic temperament had more switches into mania.

Besides influencing the clinical features of BD, affective temperaments seem to be associated with systemic alterations in individuals with mood disorders. For example, Kesebir et al. ${ }^{37}$ observed higher levels of uric acid in individuals with hyperthymic and irritable temperaments, both in patients with $B D$ and in depressed unipolar patients and normal controls. The same study encountered depressed unipolar patients and depressive temperament with lower levels of uric acid. In the study by Altinbas et al. ${ }^{38}$ with patients diagnosed with $B D$, those with depressive temperament had higher scores of metabolic syndrome in the winter.

Several clinical features are associated with changes on insight in BD patients. For example, a few studies showed correlation between lower level of insight and higher severity of affective episode or presence of psychotic symptoms.13,14 Other studies state that lower insight was associated with more hostility and lower impulse control, ${ }^{39}$ more aggressive behavior, ${ }^{40}$ and worse clinical course. ${ }^{41}$ Yet other studies found correlation between lower insight and higher impairment of cognition, especially memory, emotional learning, general intelligence and psychomotor function, comprehension and perceptual-motor skills, attention, verbal fluency and executive function, and information processing speed. ${ }^{15,16}$

This study suggests that, similar to other clinical features, affective temperament also correlates with insight in BD. However, our study has potential limitations. The sample size studied was small and the temperament evaluation was not carried out before the onset of the disease, such that the influence of the course of the disease on the temperament could not be eliminated. The current study provides preliminary evidence, and we recommend further studies on the theme to explore in detail the association between temperament and insight.

\section{Conclusion}

The level of insight in BD, in addition to being determined by the affective state of the disease and several other symptoms, is influenced by the affective temperament. Our results suggest that, in euthymia, depressive temperament is associated with better insight. In mania, depressive and anxious temperaments are linked to better insight and hyperthymic temperament is associated with worse insight. Results regarding irritable temperament were conflicting, though. There were no significant correlations between cyclothymic temperament and insight in patients in any mood state.

\section{Acknowledgements}

Coordenação de Aperfeiçoamento de Pessoal de Nível Superior (CAPES) and Fundação de Amparo à Pesquisa do Estado do Rio de Janeiro (FAPERJ) provided funding for this study.

\section{Disclosure}

No conflicts of interest declared concerning the publication of this article.

\section{References}

1. Kraepelin E. Fundamental states. In: Manic-depressive insanity and paranoia. Edinburgh: E\&S Livingstone; 1921. p. 118-32.

2. Akiskal HS, Mallya G. Criteria for the "soft" bipolar spectrum: treatment implications. Psychopharmacol Bull. 1987;23:68-73.

3. Akiskal HS. Dysthymia and cyclothymia in psychiatric practice a century after Kraepelin. J Affect Disord. 2001;62:17-31.

4. Akiskal HS. The temperamental foundations of affective disorders. In: Mundt C, Hahlweg K, Fiedler $\mathrm{P}$, eds, Interpersonal factors in the origin and course of affective disorders. London: Gaskell; 1996. p. 3-30.

5. Iasevoli F, Valchera A, Di Giovambattista E, Marconi M, Rapagnani $M P$, De Berardis $D$, et al. Affective temperaments are associated with specific clusters of symptoms and psychopathology: A crosssectional study on bipolar disorder inpatients in acute manic, mixed, or depressive relapse. J Affect Disord. 2013;151:540-50.

6. Ferreira AA, Vasconcelos AG, Neves FS, Correa H. Affective temperaments and antidepressant response in the clinical management of mood disorders. J Affect Disord. 2014;155:138141.

7. Tohen M, Bowden CL, Calabrese JR, Lin D, Forrester TD, Sachs $\mathrm{GS}$, et al. Influence of sub-syndromal symptoms after remission from manic or mixed episodes. Br J Psychiatry. 2006;189:515-9. 
8. Lewis AJ. The psychopathology of insight. $\mathrm{Br} \mathrm{J}$ Med Psychol. $1934 ; 14,332-48$.

9. Sajatovic M, Ignacio RV, West JA, Cassidy KA, Safavi R, Kilbourne $A M$, et al. Predictors of nonadherence among individuals with bipolar disorder receiving treatment in a community mental health clinic. Compr Psychiatry. 2009;50:100-7.

10. Amador XF, Flaum M, Andreasen NC, Strauss DH, Yale SA, Clark $\mathrm{SC}$, et al. Awareness of illness in schizophrenia and schizoaffective and mood disorders. Arch Gen Psychiatry. 1994;51:826-36.

11. McEvoy JP, Apperson LJ, Appelbaum PS, Ortlip P, Brecosky J, Hammill K. Insight in schizophrenia. Its relationship to acute psychopathology. J Nerv Ment Dis. 1989;177:43-7.

12. Pini S, Cassano GB, Dell'Osso L, Amador XF. Insight into illness in schizophrenia, schizoaffective and mood disorders with psychotic features. Am J Psychiatry. 2001;158:122-5.

13. Bressi $C$, Porcellana $M$, Marinaccio PM, Nocito EP, Ciabatti $M$, Magri $L$, et al. The association between insight and symptoms in bipolar inpatients: an Italian prospective study. Eur Psychiatry. 2012;27:619-24.

14. Güçlü O, Karaca $O$, Yildirim B, Ozköse MM, Erkiran M. The relationship between insight and clinical features in bipolar disorder. Turk Psikiyatri Derg. 2011;22:1-7.

15. Dias VV, Brissos S, Carita AI. Clinical and neurocognitive correlates of insight in patients with bipolar I disorder in remission. Acta Psychiatr Scand. 2008;117:28-34.

16. Van Der Werf-Eldering MJ, Van Der Meer $L$, Burger $H$, Holthausen $E A E$, Nolen WA, Aleman A. Insight in bipolar disorder: associations with cognitive and emotional processing and illness characteristics. Bipolar Disord. 2011;13:343-54.

17. Manual Diagnóstico e Estatístico de Transtornos Mentais. $5^{a}$ Edição. American Psychiatric Association (APA). Ed: Artmed. 2014.

18. Hamilton M. A rating scale for depression. J Neurol Neurosurg Psychiatry. 1960;23:56-62.

19. Young RC, Biggs JT, Ziegler VE, Meyer DA. A rating scale for mania: reliability, validity and sensitivity. Br J Psychiatry. 1978;133:42935.

20. Spearing M K, Post RM, Leverich GS, Brandt D, Nolen W. Modification of the Clinical Global Impressions (CGI) Scale for use in bipolar illness (BP): the CGI-BP. Psychiatry Res. 1997;73:15971.

21. Olaya B, Marsà F, Ochoa S, Balanzá-Martínez V, Barbeito S, García-Portilla MP, et al. Development of the insight scale for affective disorders (ISAD): Modification from the scale to assess unawareness. J Affect Disord. 2012;142:65-71.

22. Silva RA, Mograbi DC, Filgueiras A, Camelo EVM, Morton GD, Landeira-Fernandez J, et al. Cross-cultural adaptation, validation and factor structure of the Insight Scale for Affective Disorders. J Affect Disord. 2015;178:181-7.

23. Akiskal HS, Akiskal KK. TEMPS: Temperament Evaluation of Memphis, Pisa, Paris and San Diego. J Affect Disord. 2005;85:1-2.

24. Woodruff E, Genaro LT, Landeira-Fernandez J, Cheniaux E, Laks J, Jean-Loius $G$, et al. Validation of the Brazilian brief version of the temperament auto-questionnaire TEMPS-A: the brief TEMPS-Rio de Janeiro. J Affect Disord. 2011;134:65-76.

25. Koufaki I, Polizoidou V, Fountoulakis KN. The concept of temperament and its contribution to the understanding of the bipolar spectrum. Psychiatriki. 2017;28:142-55.

26. Solmi M, Zaninotto L, Toffanin T, Veronese N, Lin K, Stubbs B, et al. A comparative meta-analysis of TEMPS scores across mood disorder patients, their first-degree relatives, healthy controls, and other psychiatric disorders. J Affect Disord. 2016;196:3246 .
27. Qiu F, Akiskal HS, Kelsoe JR, Greenwood TA. Factor analysis of temperament and personality traits in bipolar patients: Correlates with comorbidity and disorder severity. J Affect Disord. 2017;207:282-90.

28. Silva RA, Mograbi DC, Silveira LAS, Nunes ALS, Novis FD, Landeira-Fernandez $\mathrm{J}$, et al. Insight across the different mood states of bipolar disorder. Psychiatr Q. 2015;86:395-405.

29. Silva RA, Mograbi DC, Camelo EVM, Bifano J, Wainstok M, Silveira LAS, et al. Insight in bipolar disorder: A comparison between mania, depression and euthymia using the Insight Scale for Affective Disorders. Trends Psychiatry Psychother. 2015;37:152-6.

30. Brieger P, Roettig S, Ehrt U, Wenzel A, Blöink R, Marneros A. T EMPS-A scale in 'mixed' and 'pure' manic episodes: new data and methodological considerations on the relevance of joint anxiousdepressive temperament traits. J Affect Disord. 2003;73:99104.

31. Roettig D, Roettig S, Brieger P, Marneros A. Temperament and personality in bipolar I patients with and without mixed episodes. J Affect Disord. 2007;104:97-102.

32. Akiskal HS, Placidi GF, Maremmani I, Signoretta S, Liguori A, Gervasi R, et al. TEMPS-I: delineating the most discriminant traits of the cyclothymic, depressive, hyperthymic and irritable temperaments in a nonpatient population. J Affect Disord. 1998; 51:7-19.

33. Russo M, Mahon K, Shanahan M, Ramjas E, Solon C, Braga RJ, et al. Affective temperaments and neurocognitive functioning in bipolar disorder. J Affect Disord. 2014;169:51-6.

34. Vöhringer PA, Whitham EA, Thommi SB, Holtzman NS, Khrad $\mathrm{H}$, Ghaemi SN. Affective temperaments in clinical practice: A validation study in mood disorders. J Affect Disord. 2012;136:57780.

35. Azorin JM, Adida M, Belzeaux R. Predominant polarity in bipolar disorders: Further evidence for the role of affective temperaments. J Affect Disord. 2015;182: 57-63.

36. Kesebir S, Vahip S, Akdeniz F, Yüncü Z, Alkana M, Akiskal H. Affective temperaments as measured by TEMPS-A in patients with bipolar I disorder and their first-degree relatives: a controlled study. J Affect Disord. 2005; 85:127-33.

37. Kesebir $S$, Ünübol $B$, Yaylacı ET, Gündoğar $D$, Ünübol H. Impact of childhood trauma and affective temperament on resilience in bipolar disorder. Int J Bipolar Disord. 2015;3:3.

38. Altinbas K, Guloksuz S, Oral ET. Metabolic syndrome prevalence in different affective temperament profiles in bipolar-I disorder. Rev Bras Psiquiatr. 2013;35:131-5.

39. Calatayud GL, Sebastián NH, García-Iturrospe EA, Piqueras JCG, Arias JS, Cercós CL. Relationship between insight, violence and diagnoses in psychotic patients. Rev Psiquiatr Salud Ment. 2012;5:43-7.

40. González-Ortega I, Mosquera F, Echeburúa E, González-Pinto A. Insight, psychosis and aggressive behaviour in mania. Eur J Psychiatry. 2010;24:70-7.

41. Ghaemi SN, Boiman E, Goodwin FK. Insight and outcome in bipolar, unipolar and anxiety disorders. Compr Psychiatry. 2000;41:167-71.

\section{Correspondence:}

Daniel C. Mograbi

Institute of Psychiatry, King's College London

PO Box 078, De Crespigny Park

SE5 8AF - London - UK

Tel.: +44 (207) 8485718

E-mail: daniel.mograbi@kcl.ac.uk 